\title{
PERCEPÇÃO AMBIENTAL DA COMUNIDADE ACADÊMICA NO CAMPUS DE ALTO ARAGUAIA DA UNIVERSIDADE DO ESTADO DE MATO GROSSO
}

\author{
Environmental Perception of the Students and Workers of a State University of \\ Mato Grosso Unit
}

Percepción Ambiental de los Estudiantes y Trabajadores de una Unidad de la Universidad del Estado de Mato Grosso

\author{
Jeferson Boldrini da Silva* \\ Fernando Thiago**
}

*Universidade do Estado de Mato Grosso - boldrinijs@unemat.br
* Universidade Federal de Mato Grosso do Sul - fernando.t@ufms.br

Recebido em 24/01/2020. Aceito para publicação em 17/03/2020

Versão online publicada em 05/05/2020 (http://seer.ufrgs.br/paraonde)

\section{Resumo:}

O objetivo desta investigação é obter um diagnóstico sobre a percepção ambiental da comunidade acadêmica (docentes, discentes e técnicos) do Campus Universitário de Alto Araguaia da Universidade do Estado de Mato Grosso (UNEMAT) e verificar o conhecimento da comunidade sobre as ações da instituição voltadas a questão ambiental que compõem os documentos de planejamento da Universidade. Foram analisados os hábitos de consumo sustentável, a percepção das questões ambientais e o conhecimento das ações institucionais relacionados ao meio ambiente. Trata-se de uma pesquisa quantitativa em que os dados foram coletados por meio de questionário estruturado e analisados por estatística descritiva. Os resultados mostram que os participantes estão cientes das questões ambientais, mantém hábitos que promovem o consumo sustentável, contudo, desconhecem o planejamento e ações institucionais em promoção à proteção ambiental.

Palavras-chave: Consumo sustentável. Percepção ambiental. Planejamento ambiental.

\begin{abstract}
:
The objective of this research is to obtain a diagnosis about the environmental perception of the academic community (teachers, students and technicians) of a unit of the State University of Mato Grosso, Brazil, and verify the knowledge of the community about the actions of the institution focused on the environmental issue that compose the planning documents of the University. We analyzed the habits of sustainable consumption, the perception of environmental issues and the knowledge of institutional actions related to the environment. It is a quantitative research in which the data were collected through a structured questionnaire and analyzed by descriptive statistics. The results show that the participants are aware of environmental issues, maintains habits that promote sustainable consumption, however, they are unaware of the planning and institutional actions in favor of environmental protection.
\end{abstract}

Key-words: Sustainable consumption. Environmental perception. Environmental planning. 


\begin{abstract}
Resumen:
El objetivo de esta investigación es obtener un diagnóstico sobre la percepción ambiental de la comunidad académica (docentes, estudiantes y técnicos) del campus de la Universidad de Mato Grosso (UNEMAT) del Alto Araguaia y verificar el conocimiento de la comunidad sobre las acciones de la institución centradas en el problema ambiental que compone los documentos de planificación de la Universidad. Se analizaron hábitos de consumo sostenibles, percepción de problemas ambientales y conocimiento de acciones institucionales relacionadas con el medio ambiente. Esta es una investigación cuantitativa en la que los datos fueron recolectados a través de un cuestionario estructurado y analizados por estadística descriptiva. Los resultados muestran que los participantes son conscientes de los problemas ambientales, mantienen hábitos que promueven el consumo sostenible, sin embargo, desconocen la planificación y las acciones institucionales para promover la protección del medio ambiente.
\end{abstract}

Palabras-clave: Consumo sostenible. Percepción ambiental. Planificación ambiental.

\title{
1. Introdução
}

O relacionamento com o ambiente e com os demais seres vivos, juntamente com o desenvolvimento científico e tecnológico, permite a alteração dos padrões de consumo e produção, além de modificar o meio em que vivemos. Na maioria das vezes, os impactos dessas ações não são percebidos e acabam sendo ignorados. Baumont, Girardi e Pedroso (2008) apontam que apesar de existirem ferramentas que possam identificar problemas ambientais, ainda assim, pouco se compreende cada um deles e na maioria dos casos, são classificados como de difícil resolução.

Questões ambientais se fazem cada vez mais presentes na pauta tanto da mídia de maneira geral quanto nas discussões acadêmicas. Isso se deve, em grande parte, pelas discussões promovidas em âmbito global, como as realizadas pelo Relatório de Brundtland em 1987, pela ECO 92 e a Rio+20, e também pela importância e necessidade de informação sobre os acontecimentos envolvendo o meio ambiente para que as pessoas possuam condições de modificar, de maneira consciente e sustentável, o cenário ambiental, promovendo maior qualidade de vida. Desde então, percebe-se uma crescente preocupação em tornar mais sustentável nosso estilo de vida.

Nesse sentido, as Instituições de Ensino Superior (IES) se apresentam como espaços em potencial na contribuição do Desenvolvimento Sustentável. Tendo em vista que por meio do ensino, pesquisa e extensão buscam formar profissionais que atuem efetivamente, em diferentes grupos, instituições e níveis em lugares onde está necessidade de sustentabilidade se faz presente. Logo, elas mesmas devem ser exemplos para vivência e execução de práticas sustentáveis.

O Campus Universitário de Alto Araguaia foi criado no ano de 1991 e está localizado a uma distância de aproximadamente $400 \mathrm{~km}$ da capital do Estado, Cuiabá. São oferecidos no campus quatro cursos na modalidade regular e presencial: Licenciatura em Letras, Licenciatura em Computação, Bacharelado em Jornalismo e Bacharelado em Ciência da Computação e dois

ParaOnde!?, Porto Alegre, v.13, n.2, p.28-42, 2020.http://seer.ufrgs.br/paraonde Edição Especial - VII Seminário Internacional de Estudos Fronteriços 
de oferta diferenciada com disciplinas em módulos, denominada modalidade "parceladas": Bacharelado em Direito e Licenciatura em Pedagogia.

Esta unidade faz parte da Universidade do Estado de Mato Grosso, presente em todas as regiões de Mato Grosso em seus 13 campus e 24 núcleos pedagógicos de ensino à distância e 23 núcleos pedagógicos de modalidades diferenciadas.

O objetivo desta investigação é obter um diagnóstico sobre a percepção ambiental da comunidade acadêmica (docentes, discentes e técnicos) do Campus Universitário de Alto Araguaia da Universidade do Estado de Mato Grosso (Unemat), assim como verificar o conhecimento da comunidade sobre as ações da instituição voltadas a questão ambiental que compõem os documentos de planejamento da Universidade.

\section{Desenvolvimento}

\section{Fundamentação Teórica}

A preocupação com questões ambientais tem ganhado notoriedade nas últimas décadas, das quais incluem os temas sobre escassez dos recursos naturais. Diante do fato de que estes recursos são matéria prima para produtos e serviços, hábitos de consumo sustentável são emergentes, visto o crescimento da população mundial.

Em 1987, o Relatório de Brundtland, conhecido como "Nosso Futuro Comum", traz uma forma de pensar num consumo mais consciente, apresentando o conceito do tripé da sustentabilidade (WCED 1987), abrangendo os aspectos econômicos, sociais e ambientais, com objetivos de utilizar os recursos de maneira que não afetem as gerações futuras.

Assadourian (2010) afirma que a forma vigente pode comprometer essas gerações futuras, sendo considerada uma barreira para a sustentabilidade, especialmente pelo modelo de consumo dos países mais desenvolvidos.

O consumo é um hábito de uma pessoa ou grupos de pessoas que são influenciadas pelos valores sociais, sendo inclusive um conjunto de significados para as pessoas (DE TONI et al., 2010). Neste aspecto, é inerente realizar estudos para compreender os principais padrões de consumo, como forma de diagnóstico, para proposição de novos modelos (JACKSON, 2004).

De acordo com Silva, Oliveira e Gómez (2013, p. 175), consumo consciente "envolve a escolha de produtos ambientalmente corretos com menor impacto ambiental no pós-consumo ou de produtos de empresas socialmente justas", ou como definido por Fabi et al. (2010, p. 6) sendo "o ato ou decisão de compra ou uso de serviços, de bens industriais ou naturais, praticado por um indivíduo levando em conta o equilíbrio entre satisfação pessoal, as possibilidades ambientais e os efeitos sociais de sua decisão".

Consumir é uma ação social inerente ao estilo de vida atual da humanidade e, além disso, dinamiza a economia. Contudo, o atual modelo vigente de consumo da sociedade moderna, acelera o desgaste dos recursos

ParaOnde!?, Porto Alegre, v.13, n.2, p.28-42, 2020.http://seer.ufrgs.br/paraonde Edição Especial - VII Seminário Internacional de Estudos Fronteriços 
naturais, com usos, na maioria dos casos, desnecessários (COSTA; TEODÓSIO, 2011).

O atual modelo de desenvolvimento econômico estabelece esta nova forma de consumo, gerando a atual crise ambiental, com danos ambientais, ecológicos e aumento nas desigualdades sociais (GUIMARÃES, 2001).

Para Guimarães (2001) uma mudança urgente nos padrões de consumo seria necessária para o desenvolvimento sustentável, estabelecendo novos limites de consumo, além de mudanças nos padrões morais, do ponto de vista das atitudes individuais, como também nas ações públicas.

As mudanças nas atitudes individuais podem fazer com que as pessoas passem a consumir produtos ecologicamente correto e que promovam a qualidade de vida das pessoas, que por sua vez impacta diretamente na economia, promovendo que as empresas passem a fornecer este tipo de produto. Do ponto de vista das ações públicas, o Estado como regulador, cria leis e normas para promover o uso sustentável dos recursos naturais, que neste caso, obrigando que as empresas comercializem produtos e serviços minimizando seus impactos no meio ambiente (GUIMARÃES, 2001).

Neste ponto, uma unidade universitária possui ambiente ímpar para a sensibilização da sustentabilidade ambiental, primeiro por meio de sua função fim, a educação, discutindo no seu curriculum este assunto, segundo, pela sua gestão, promovendo atitudes ecológica e socialmente corretas, inclusive de consumo, estabelecendo normas e procedimentos que influenciam as ações de seus trabalhadores e usuários da instituição.

Apoiando este argumento, Dias (2015) aponta que a implementação de ações que busquem a sustentabilidade e o desenvolvimento sustentável pode contribuir na mudança de hábito.

O Desenvolvimento Sustentável constitui uma nova vertente de análise, que busca na utilização de novas abordagens e na interdisciplinaridade um caminho que nos permita superar de modo integral a dicotomia entre crescimento econômico e meio ambiente (DIAS, 2015, p.25).

Para Sorrentino, Nascimento e Portugual (2011) as IES podem cumprir dois papéis durante os processos de formação: o primeiro seria de educar a própria instituição para incorporar a questão ambiental em seu dia a dia, e o segundo seria o de contribuir na educação ambiental da sociedade. Nesse sentido, o estudo da Percepção Ambiental (PA) se apresenta como ferramenta valiosa para compreender como os diferentes membros envolvidos veem, agem e se relacionam com o ambiente, gerando dados que podem servir para tomada de decisões do gestor e definição de estratégias.

Logo, "[...] o uso da PA como instrumento de gestão, apresenta um grande potencial de uso, além de ser um poderoso instrumento no âmbito das atividades educacionais, sustentando e estimulando atividades multi ou interdisciplinares" (FERNANDES, 2004, p. 13).

Falar sobre a construção de sociedades sustentáveis pela via educacional exige aprofundar-se, simultaneamente, em conhecimentos e em

ParaOnde!?, Porto Alegre, v.13, n.2, p.28-42, 2020.http://seer.ufrgs.br/paraonde Edição Especial - VII Seminário Internacional de Estudos Fronteriços 
propostas de ações que envolvam a formulação e a implantação de políticas públicas e o aprimoramento dos métodos e técnicas de ensino e aprendizagem que permitam tais estudos, debates e aprendizados (SORRENTINO; NASCIMENTO; PORTUGUAL, 2011, p. 20).

Fróes, Milanezi e Bogarim (2011), afirmam que para a Universidade cumprir o seu papel no desenvolvimento de uma sociedade sustentável é importante que estas instituições construam um plano de desenvolvimento institucional (PDI) incluindo objetivos e ações que atendam valores, ações e princípios ambientalmente sustentáveis. Além disso, devem promover o engajamento e interação com o meio ambiente por meio de sua comunidade acadêmica. De acordo com Caramez e Cooper (2011), o sucesso de metodologias participativas advém da intensa participação de toda a comunidade.

Neste aspecto, Robbins e Decenzo (2004) ainda enfatizam a importância da participação das pessoas em todo o processo, uma vez que se a participação se efetivar, as pessoas endossarão a decisão, proporcionando resultados mais eficazes.

Diante disso, a análise da literatura observada proporciona olhares sobre a percepção de acadêmicos, sobre seus conhecimentos das questões ambientais, hábitos de consumo e conhecimento sobre as ações institucionais pertinentes ao planejamento e desenvolvimento de ações sensíveis às questões ambientais, itens relevantes para atendimento dos objetivos propostos.

\section{Metodologia}

Para o desenvolvimento deste trabalho foi utilizado um estudo do tipo quantitativo e descritivo. Conforme Gil (2008), estes tipos de pesquisas têm como objetivo descrever um determinado fenômeno por meio de técnicas de observação e coleta de dados.

As técnicas de pesquisa utilizadas foram a pesquisa documental e levantamento (survey). A primeira consiste na análise de material escrito sem algum tipo de tratamento analítico (GIL, 2008), a segunda consiste no levantamento de dados diretamente com o público que se deseja investigar, inquerindo sobre seu comportamento ou opinião (GIL, 2008; FOWLER JR., 2011).

A amostra foi selecionada por acessibilidade, caracterizada como não probabilística. Neste tipo de amostragem, mesmo que se tenha acesso a toda a população investigada, utiliza-se apenas as respostas dos que se mostraram acessíveis para participar (COSTA NETO, 1977). Assim, toda a comunidade acadêmica foi convidada a participar, contudo, apenas 87 responderam 0 questionário.

A população-alvo desta pesquisa foi a comunidade acadêmica do Campus Universitário de Alto Araguaia da Universidade do Estado de Mato Grosso. A comunidade acadêmica, no período 2018/2, de acordo com dados

ParaOnde!?, Porto Alegre, v.13, n.2, p.28-42, 2020.http://seer.ufrgs.br/paraonde Edição Especial - VII Seminário Internacional de Estudos Fronteriços 
fornecidos pelos setores de Recursos Humanos e Supervisão de Apoio Acadêmico do Campus, possuiu a seguinte composição: 61 docentes, 30 técnicos e 494 discentes.

Dois documentos bases para as ações da gestão foram alvo de análise documental para essa investigação, sendo eles: O Planejamento Estratégico Participativo 2015-2025 (PEP) e o Plano de Desenvolvimento Institucional 2017-2021 (PDI). Buscou-se por meio deste método localizar os objetivos descritos nestes documentos que envolvam diretamente questões ambientais.

Foi aplicado um questionário estruturado com dezoito perguntas divididas nas seguintes seções: perfil socioeconômico, hábitos no campus, e a relação da Universidade com as questões ambientais. A coleta de dados foi realizada no período de novembro a dezembro de 2018.

Oliveira (2011) define questionário como uma série ordenada de questões, podendo ser respondida com ou sem a presença do pesquisador. Este tipo de ferramenta tem se demonstrado eficaz na obtenção de dados sobre comportamento do consumidor.

As perguntas foram disponibilizadas para preenchimento na plataforma de questionários online Google Forms $\AA^{\circledR}$ e 0 link do formulário foram encaminhados para os e-mails dos membros da comunidade acadêmica, conforme os dados de contato que constam nas listas disponibilizadas pela instituição. O questionário foi elaborado utilizando os modelos de Fernandes (2004) e Fróes, Milanezi e Bogarim (2011).

Os dados coletados foram tabulados e analisados por meio estatística descritiva, especificamente de frequências. Os dados levantados pela pesquisa documental foram extraídos e analisados por seu conteúdo conforme procedimento de extração, codificação e análise descritas por Bardin (1977).

\section{Resultados e Discussões}

Ao todo 87 pessoas que integram a comunidade acadêmica do campus universitário de Alto Araguaia da UNEMAT responderam o questionário, sendo $16 \%$ integrantes da categoria Docente, $13 \%$ da categoria Técnico e $71 \%$ da categoria discente (Figura 1).

ParaOnde!?, Porto Alegre, v.13, n.2, p.28-42, 2020.http://seer.ufrgs.br/paraonde Edição Especial - VII Seminário Internacional de Estudos Fronteriços 
Figura 1. Porcentagem de participantes da pesquisa organizada por categoria da comunidade acadêmica
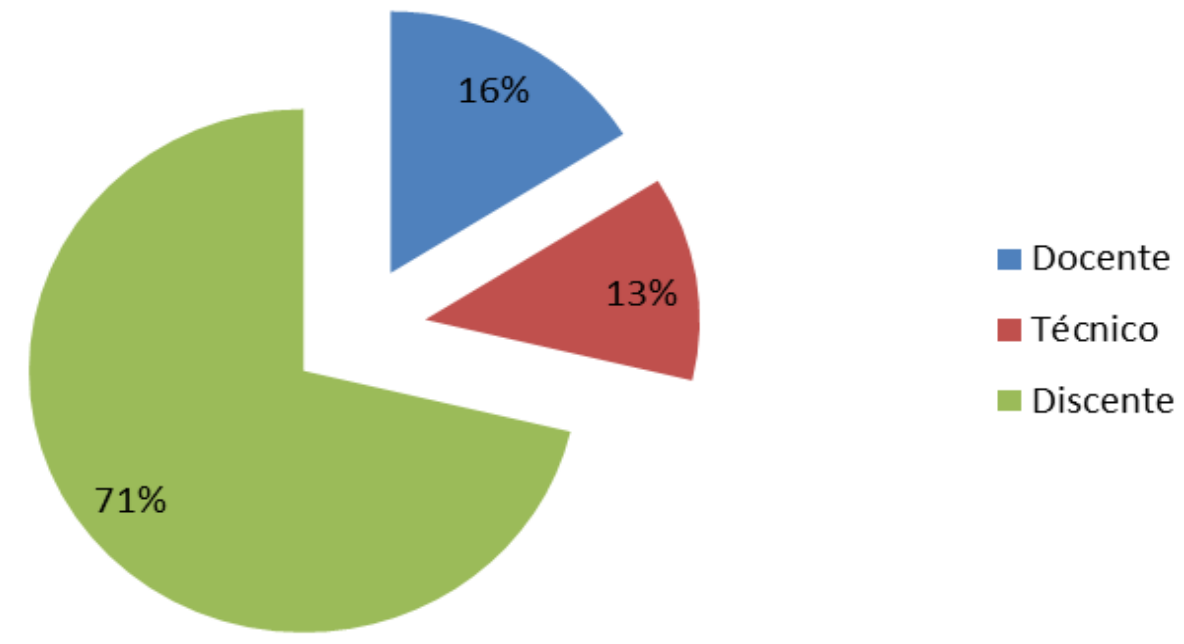

Fonte: Dados da pesquisa (2018).

Destes, 95\% admitem possuir interesse em assuntos relacionados ao meio ambiente, conforme pode ser observado na Figura 2.

Figura 2. Porcentagem de interesse em assuntos ambientais

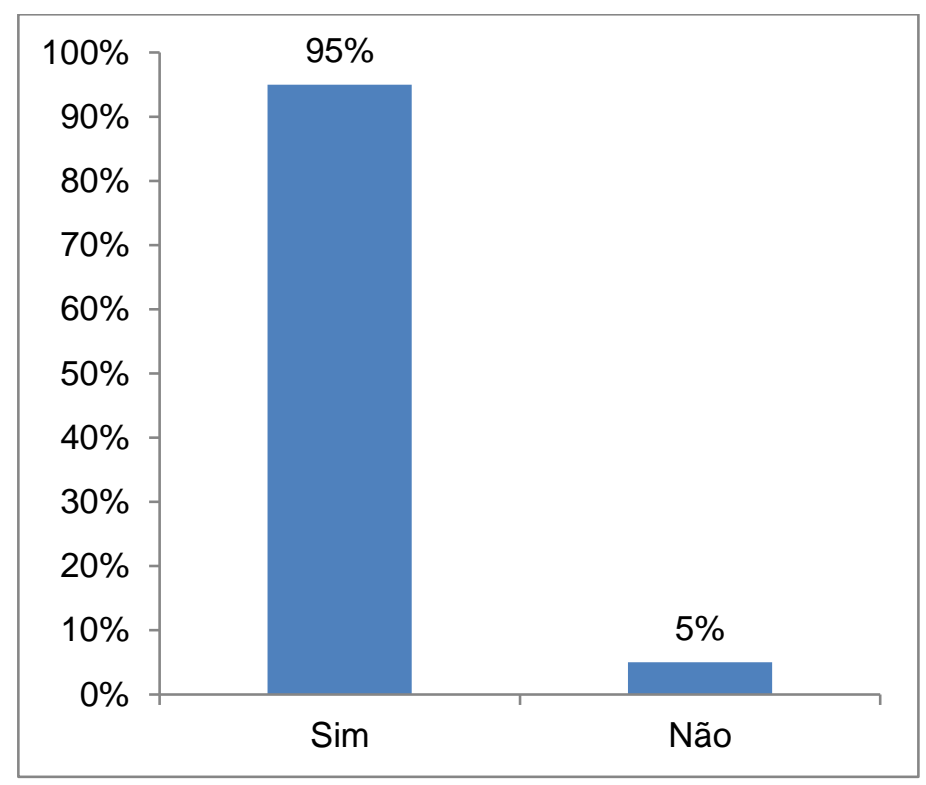

Fonte: Dados da pesquisa (2018).

Outro aspecto questionado foi sobre a frequência de incômodo com aspectos negativos que estão relacionados ao meio ambiente, como a poluição, desmatamento, aquecimento global, entre outros. A Figura 3 apresenta que $85 \%$ dos participantes frequentemente e sempre se incomodam com os aspectos negativos gerados ao meio ambiente. Cabe ressaltar que nenhum dos respondentes marcou a opção "nunca", desta questão. 

ambiente.

Figura 3. Frequência de incomodo com aspectos negativos do meio

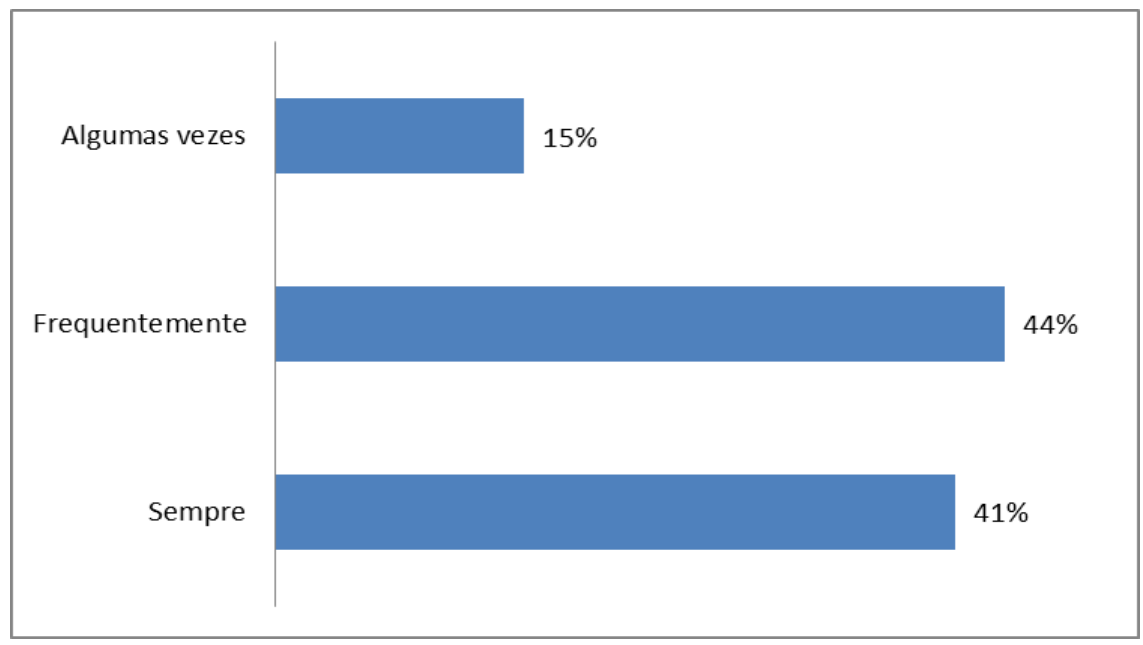

Fonte: Dados da pesquisa (2018).

Esses dados demonstram que existe uma preocupação com as questões ambientais por parte da comunidade acadêmica, se apresentando como uma vertente importante para o planejamento institucional. Marques, Marchetto, Temponi e Ferreira Leite (2014) apontam que o meio ambiente se tornou um fator de importância para o processo de decisão das empresas, garantindo a competitividade e sobrevivência no mundo globalizado. Para Sorrentino, Nascimento e Portugual (2011), a Universidade tem um papel a cumprir nesse cenário: definir com seus participantes e com a sociedade que a mantêm que direção seguir e como o fazer.

A preocupação com a questão ambiental influencia nos hábitos das pessoas no campus universitário. A maioria dos entrevistados apontou que sempre realiza ações que contribuem para a sustentabilidade ou diminuem o impacto no meio ambiente conforme apresentado na Tabela 1.

Tabela 1. Hábitos da comunidade acadêmica

\begin{tabular}{lccccc}
\hline Hábitos & Sempre & Frequentemente & $\begin{array}{c}\text { Algumas } \\
\text { vezes }\end{array}$ & $\begin{array}{c}\text { Pouquíssimas } \\
\text { vezes }\end{array}$ & Nunca \\
\hline $\begin{array}{l}\text { Apaga luzes e outros } \\
\text { aparelhos quando deixa o } \\
\text { ambiente no campus }\end{array}$ & $48 \%$ & $28 \%$ & $17 \%$ & $4 \%$ & $3 \%$ \\
$\begin{array}{l}\text { Utiliza corretamente as } \\
\text { lixeiras de coleta seletiva } \\
\text { no campus }\end{array}$ & $54 \%$ & $20 \%$ & $22 \%$ & $3 \%$ & $1 \%$ \\
$\begin{array}{l}\text { Utilizam os dois lados } \\
\text { dos papéis ou reutiliza } \\
\text { rascunhos }\end{array}$ & $47 \%$ & $31 \%$ & $16 \%$ & $6 \%$ & - \\
$\begin{array}{l}\text { Evita realizar impressões } \\
\text { desnecessárias }\end{array}$ & $60 \%$ & $29 \%$ & $9 \%$ & $2 \%$ & - \\
$\begin{array}{l}\text { Utiliza próprio copo, } \\
\text { garrafa de água ou } \\
\text { reutiliza o mesmo copo. }\end{array}$ & $68 \%$ & $17 \%$ & $10 \%$ & $2 \%$ & $2 \%$ \\
\hline Fonte: Dados da prqusa & & & & & \\
\hline
\end{tabular}

Fonte: Dados da pesquisa (2018).

ParaOnde!?, Porto Alegre, v.13, n.2, p.28-42, 2020.http://seer.ufrgs.br/paraonde Edição Especial - VII Seminário Internacional de Estudos Fronteriços 
A preocupação com a questão ambiental influencia nos hábitos das pessoas no campus universitário. A maioria dos entrevistados apontou que sempre realiza ações que contribuem para a sustentabilidade ou diminuem o impacto no meio ambiente conforme apresentado na Tabela 1.

Os dados mostram que $68 \%$ admitiram sempre utilizar o próprio copo/garrafa de água e 60\% disseram sempre evitar imprimir coisas desnecessárias. Marques, Marchetto, Temponi e Ferreira Leite (2014) afirmam que a percepção ambiental da comunidade acadêmica é relevante no momento que ela própria se considera causadora dos danos e responsável na proteção do meio ambiente, se comprometendo com questões ambientais.

Ao serem questionados sobre como percebem a relação da Universidade com o Meio Ambiente, a maioria dos entrevistados (54\%) admitiu não possuir elementos para opinar sobre, enquanto $18 \%$ acredita que a Universidade investe em meio ambiente, mas ainda causa danos a ele (Figura 4).

Figura 4. Percepção da comunidade acadêmica sobre a relação da Universidade com o Meio Ambiente
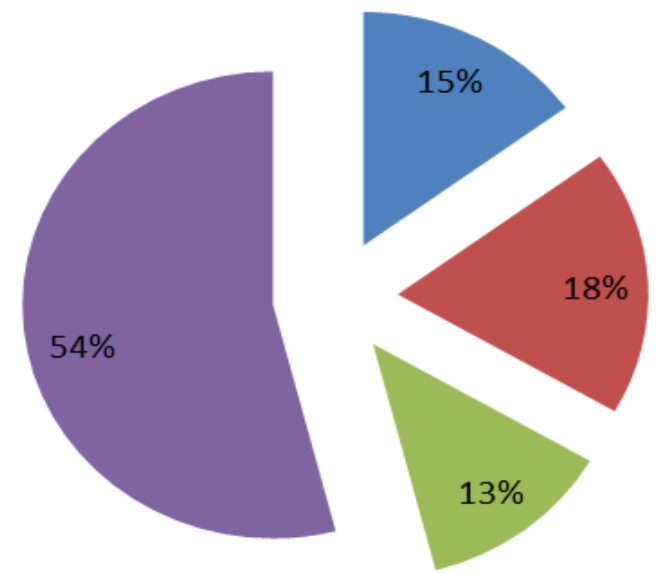

Investe em meio
ambiente e cumpre
exigências ambientais
Investe em meio
ambiente, mas ainda
causa danos a ele
Não investe em meio
ambiente e não cumpre
exigências ambientais
Não tenho elementos
para opinar sobre

Fonte: Dados da pesquisa (2018).

Neste aspecto, Caramez e Cooper (2011) apontam que a inserção da sustentabilidade no meio universitário se apresenta como um processo transformador que é desencadeado por um demasiado esforço da instituição e pela inclusão de toda a comunidade nas discussões e tomada de decisões.

Observa-se que individualmente as pessoas possuem atitudes e sensibilidade às questões ambientais, sendo uma das partes importantes na mudança dos hábitos de consumo que promovam a sustentabilidade nos termos que Guimarães (2001) propõe.

A próxima análise trata sobre os aspectos regulatórios e do planejamento da organização. Como mencionado anteriormente, na Universidade do Estado de Mato Grosso, dois documentos são bases para as ações da gestão e de toda a comunidade acadêmica, sendo eles: $O$ Planejamento Estratégico Participativo 2015-2025 (PEP) e o Plano de Desenvolvimento Institucional 2017-2021 (PDI).

ParaOnde!?, Porto Alegre, v.13, n.2, p.28-42, 2020.http://seer.ufrgs.br/paraonde Edição Especial - VII Seminário Internacional de Estudos Fronteriços 
O PEP traça objetivos estratégicos, metas e ações a curto, médio e longo prazo. Para o estabelecimento dessas ações, foram realizadas discussões em todos os campus com representantes de todos os segmentos. Tais discussões culminaram nos objetivos, metas e estratégias que devem guiar a gestão e a comunidade acadêmica num prazo de dez anos (UNEMAT, 2016).

O PDI foi elaborado tendo como base o PEP e apresenta 0 planejamento da Universidade, no prazo de cinco anos, por meio de ações distribuídas em cinco dimensões. Estas dimensões estão assim estabelecidas: Política de ensino, pesquisa, extensão e gestão universitária; Política de pessoal; Infraestrura física, tecnológica e patrimonial; Gestão orçamentária e financeira; Políticas de avaliação, acompanhamento e monitoramento das ações (UNEMAT, 2017).

O PEP apresenta 7 objetivos estratégicos diretamente ligados a questão ambiental (Quadro 1). Esses objetivos devem ser alcançados pela comunidade acadêmica por meio de tarefas e ações a serem implementados por diferentes setores/grupos ao longo de diferentes prazos. No PDI os objetivos estratégicos definidos no PEP se repetem, não havendo o estabelecimento de novas metas.

Quadro 1. Objetivos Estratégicos voltados diretamente a questão ambiental definidos no PEP 2015-2025

\begin{tabular}{|c|c|c|c|c|}
\hline $\begin{array}{l}\text { Setor } \\
\text { responsável }\end{array}$ & $\begin{array}{l}\text { Objetivos } \\
\text { estratégicos }\end{array}$ & $\begin{array}{l}\text { Tarefas/ações a serem } \\
\text { implementadas }\end{array}$ & Prioridade & $\begin{array}{l}\text { Tempo dos } \\
\text { objetivos }\end{array}$ \\
\hline PROEC & $\begin{array}{l}\text { Consolidar } \\
\text { participação da } \\
\text { comunidade } \\
\text { acadêmica em projetos } \\
\text { a serem aplicados nos } \\
\text { campi e territórios de } \\
\text { entorno, sobre a } \\
\text { interação entre o ser } \\
\text { humano e o ambiente. }\end{array}$ & $\begin{array}{l}1 \text { Estimular a } \\
\text { participação de } \\
\text { discentes em projetos } \\
\text { de ensino, extensão e } \\
\text { pesquisa. } \\
2 \text { - Aumentar a } \\
\text { quantidade de bolsas de } \\
\text { ensino, pesquisa e } \\
\text { extensão. } \\
3 \text { - Criar política de } \\
\text { parceria para bolsas } \\
\text { com empresas privadas } \\
\text { e demais instituições. } \\
4 \text { - Aumento do auxílio } \\
\text { financeiro } \\
\text { participação para } \\
\text { eventos. em } \\
5 \text { - Fomentar a abertura } \\
\text { de editais de ensino, } \\
\text { pesquisa e extensão } \\
\text { que proporcionem } \\
\text { interação entre o ser } \\
\text { humano e o ambiente. }\end{array}$ & $\begin{array}{l}\text { Alta } \\
\text { urgência }\end{array}$ & $\begin{array}{l}\text { Objetivos de } \\
\text { longo prazo } \\
\text { (até 2025) }\end{array}$ \\
\hline PROEC & $\begin{array}{l}\text { Desenvolver Política de } \\
\text { Sustentabilidade da } \\
\text { Unemat }\end{array}$ & $\begin{array}{l}\text { 1- Desenvolver } \\
\text { programas de educação } \\
\text { ambiental }\end{array}$ & $\begin{array}{l}\text { Urgência } \\
\text { moderada }\end{array}$ & $\begin{array}{l}\text { Objetivos de } \\
\text { longo prazo } \\
\text { (até 2025) }\end{array}$ \\
\hline DPPF & $\begin{array}{l}\text { Desenvolver Política de } \\
\text { Sustentabilidade da } \\
\text { Unemat }\end{array}$ & $\begin{array}{l}\text { 1- "Aquisições } \\
\text { sustentáveis", como por } \\
\text { exemplo: equipamentos }\end{array}$ & $\begin{array}{l}\text { Urgência } \\
\text { moderada }\end{array}$ & $\begin{array}{l}\text { Objetivos de } \\
\text { longo prazo } \\
\text { (até 2025) }\end{array}$ \\
\hline
\end{tabular}

ParaOnde!?, Porto Alegre, v.13, n.2, p.28-42, 2020.http://seer.ufrgs.br/paraonde Edição Especial - VII Seminário Internacional de Estudos Fronteriços 


\begin{tabular}{|c|c|c|c|c|}
\hline & & $\begin{array}{l}\text { com alta eficiência } \\
\text { energética, materiais } \\
\text { reciclados. } \\
\text { 2- Estudar o impacto e a } \\
\text { demanda para os novos } \\
\text { cursos e novos câmpus } \\
\text { a serem implantados. }\end{array}$ & & \\
\hline DPPF & $\begin{array}{l}\text { Ter amplos espaços } \\
\text { para infraestrutura } \\
\text { como salas de aula, } \\
\text { banheiros, laboratórios, } \\
\text { bibliotecas, auditórios } \\
\text { de acordo com um } \\
\text { planejamento } \\
\text { arquitetônico mais } \\
\text { moderno e com } \\
\text { princípios de } \\
\text { sustentabilidade e } \\
\text { acessibilidade. }\end{array}$ & $\begin{array}{l}\text { 1- Contratação de } \\
\text { empresa especializada } \\
\text { para elaboração de } \\
\text { projetos básicos e } \\
\text { executivos a fim de } \\
\text { atender a Universidade. } \\
\text { 2- Participação dos } \\
\text { discentes na elaboração } \\
\text { dos projetos. } \\
\text { 3- Garantir que a } \\
\text { sustentabilidade esteja } \\
\text { presente em todos os } \\
\text { projetos de engenharia } \\
\text { e arquitetura da } \\
\text { Unemat. } \\
\text { 4- Elaboração de Plano } \\
\text { Diretor para cada } \\
\text { campus. }\end{array}$ & $\begin{array}{l}\text { Alta } \\
\text { urgência }\end{array}$ & $\begin{array}{l}\text { Objetivos de } \\
\text { longo prazo } \\
\text { (até 2025) }\end{array}$ \\
\hline DURA & $\begin{array}{l}\text { Descartar resíduos de } \\
\text { forma correta e } \\
\text { contínua }\end{array}$ & $\begin{array}{l}\text { 1- Realizar Estudo de } \\
\text { descarte de resíduos. } \\
\text { 2- Instituir a comissão } \\
\text { permanente de } \\
\text { resíduos. } \\
\text { 3- Executar o Plano de } \\
\text { Descarte de Resíduos } \\
\text { sistematicamente. } \\
\text { 4- Criar política/plano de } \\
\text { tratamento de resíduos. }\end{array}$ & $\begin{array}{l}\text { Alta } \\
\text { urgência }\end{array}$ & $\begin{array}{l}\text { Objetivos de } \\
\text { curto prazo } \\
(2016 / 2017)\end{array}$ \\
\hline DURA & $\begin{array}{l}\text { Adequar o sistema de } \\
\text { saneamento básico, } \\
\text { rede elétrica e de } \\
\text { drenagem dos campi }\end{array}$ & $\begin{array}{l}\text { 1- Contratação de } \\
\text { empresa especializada } \\
\text { para elaboração de } \\
\text { projetos básicos e } \\
\text { executivos a fim de } \\
\text { atender a Universidade. } \\
\text { 2- Contratação de } \\
\text { empresa especializada } \\
\text { em execução de } \\
\text { projetos básicos e } \\
\text { executivos a fim de } \\
\text { atender a Universidade. }\end{array}$ & $\begin{array}{l}\text { Alta } \\
\text { urgência }\end{array}$ & $\begin{array}{l}\text { Objetivos de } \\
\text { médio prazo } \\
\text { (até 2019) }\end{array}$ \\
\hline DURA & $\begin{array}{l}\text { Desenvolver Política de } \\
\text { Sustentabilidade da } \\
\text { Unemat }\end{array}$ & $\begin{array}{l}1-\quad \text { Desenvolver } \\
\text { ações e estratégias } \\
\text { voltadas para o } \\
\text { gerenciamento de } \\
\text { resíduos }\end{array}$ & $\begin{array}{l}\text { Urgência } \\
\text { moderada }\end{array}$ & $\begin{array}{l}\text { Objetivos de } \\
\text { longo prazo } \\
\text { (até 2025) }\end{array}$ \\
\hline
\end{tabular}

Fonte: Adaptado de UNEMAT (2016).

O Quadro 1 apresenta ações extraídas dos instrumentos de planejamento da instituição que trataram direta ou indiretamente de questões ambientais e/ou de sustentabilidade ambiental. Estão divididas em três temas:

ParaOnde!?, Porto Alegre, v.13, n.2, p.28-42, 2020.http://seer.ufrgs.br/paraonde Edição Especial - VII Seminário Internacional de Estudos Fronteriços 
(1) Estímulo ao desenvolvimento de projetos acadêmicos - pesquisa, ensino e extensão;

(2) Explicitamente no âmbito da gestão, foi destacado o desenvolvimento de ações que promovam a educação ambiental (um item) e promover a sustentabilidade da estrutura física nos projetos de engenharia (um item). Ainda na gestão, registraram-se cinco itens a respeito da gestão de resíduos, com a gestão e criação de comissão para tratar do descarte adequado dos mesmos.

(3) Em dois itens foram tratado de forma implícita as questões de sustentabilidade ambiental quando tratado da elaboração e execução de projetos básicos.

Questionados se conhecem estes documentos e os aspectos ambientais que abordam, $72 \%$ declararam desconhecer tais documentos, enquanto $12 \%$ conhecem e veem que a questão ambiental está em pauta e devidamente aplicada nos documentos e em suas metas e ações e outros $16 \%$ conhecem os documentos e acreditam que eles deixam a desejar nos aspectos que tangem a questão ambiental (Figura 5).

Figura 5. Percepção da comunidade acadêmica sobre o tratamento da questão ambiental no PEP e PDI da Universidade

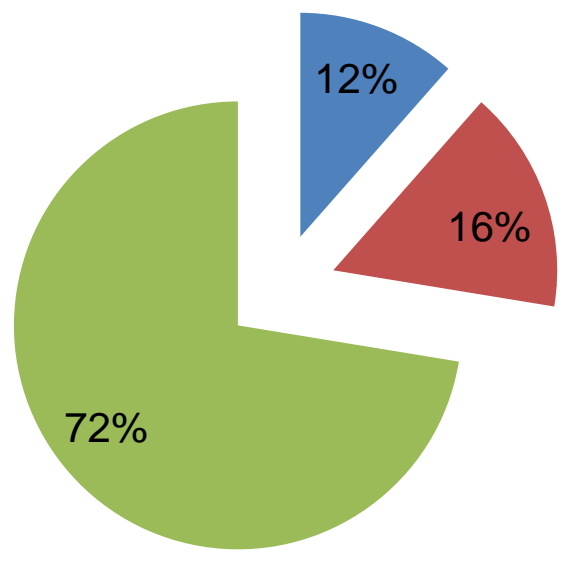

- Conhece e vê que a questão ambiental está pautada e aplicada corretamente

- Conhece e vê que eles deixam a desejar em aspectos da questão ambiental

Fonte: Dados da pesquisa (2018).

Do ponto de vista regulatório, em seu planejamento a organização contempla ações importantes para promoção da saúde ambiental, contudo, os dados demostram que os participantes da pesquisa desconhecem tais documentos.

Isso pode dificultar o alcance das metas estabelecidas, uma vez que todos os envolvidos devem estar cientes do caminho a ser traçado, e que o resultado no alcance das metas pressupõe a coparticipação de todos na

ParaOnde!?, Porto Alegre, v.13, n.2, p.28-42, 2020.http://seer.ufrgs.br/paraonde Edição Especial - VII Seminário Internacional de Estudos Fronteriços 
execução das ações planejadas. são:

Diante disso, as hipóteses possíveis sobre os pontos aqui levantados

1) A comunidade acadêmica pode não ter participado do planejamento destas ações e de sua regulação. Tanto o PEP como o PDI devem ser elaborados com a participação dos técnicos, professores e alunos por meio de seus representantes. Caso tenha ocorrido essa participação, podem ter ocorrido problemas de legitimidade dos representantes ou de comunicação das ações desenvolvidas por estes representantes.

2) O planejamento pode não ter sido concretizado, visto que algumas ações deveriam ter sido realizadas, como as de médio e curto prazo.

3) Por último, problemas de ruídos na comunicação institucional ou acompanhamento do planejamento pode causar desconhecimento das ações planejadas e efetivadas, tanto no âmbito da unidade pesquisada, o Campus, como em toda a universidade.

Estas possibilidades podem ser investigadas pela gestão com objetivos de melhorar os aspectos aqui diagnosticados, permitindo melhor eficiência na aplicação do planejamento institucional.

\section{Considerações finais}

O estudo demonstra que há uma preocupação com os aspectos ambientais pela comunidade acadêmica do campus de Alto Araguaia, havendo certo equilíbrio entre o grau de percepção e hábitos no campus universitário. Entretanto, também fica constatado um elevado grau de desconhecimento dos documentos que baseiam o desenvolvimento da instituição (PEP e PDI) e os aspectos ambientais que os mesmos abrangem. Desconhecer estes documentos faz com que os acadêmicos construam uma visão de que a Universidade deixa a desejar em relação a questões ambientais, além de prejudicar o alcance desses objetivos propostos.

Essas informações podem ser úteis para conhecer, no sentido de fornecer informações sobre como a comunidade acadêmica pensa e age, assim como para nortear as ações da gestão a fim de mobilizar a comunidade acadêmica para o conhecimento das metas e objetivos a serem alcançados, engajando-os no cumprimento das ações. Dessa forma, garante-se a participação efetiva de todos os atores no processo, promovendo os vieses de democracia e de educação participativa, essenciais na vivência universitária.

Para futuras pesquisas, sugere-se a investigação das hipóteses levantadas na seção de resultados, como também a aplicação desta pesquisa em todas as outras unidades da Universidade, verificando se estes resultados são exclusivos da unidade ou se é um diagnóstico presente em toda a Universidade, visto que a mesma está presente em grande parte do território do Estado de Mato Grosso, que por sua vez está presente em três diferentes biomas: cerrado, Amazônia e pantanal.

ParaOnde!?, Porto Alegre, v.13, n.2, p.28-42, 2020.http://seer.ufrgs.br/paraonde Edição Especial - VII Seminário Internacional de Estudos Fronteriços 


\section{Referências}

ASSADOURIAN, E. Ascensão e Queda das Culturas de Consumo. In: WORLDWATCH INSTITUTE. Estado do Mundo, 2010: estado do consumo e o consumo sustentável. Salvador: 2010.

BARDIN, L. Análise de conteúdo. Lisboa: Edições 70, 1977.

BAUMONT, C.; GIRARDI, I.M.T.; PEDROSO, R.N. Jornalismo e cidadania ecológica: análise da temática do aquecimento global no Caderno Ambiente do jornal Zero Hora. In: GIRARDI, I.M.; SCHWAAB, R.T.; MARCONDES, A.W. ... [et al.]. Jornalismo ambiental: desafios e reflexões. Porto Alegre: Ed. Dom Quixote, 2008, p.189-209.

CARAMEZ, R. B.; COOPER, M. Plano Diretor para a Gestão Ambiental Universitária: A Experiência do Campus "Luiz Queiroz" da Universidade de São Paulo (USP). In: Visões e experiências ibero-americana de sustentabilidade nas universidades: desdobramentos do $3^{\circ}$ Seminário Internacional de Sustentabilidade $\mathrm{n}$ Universidade. São Carlos/SP: USP/UAM/PUCRS. 2011. p. 97-102.

COSTA NETO, P. L. O. Estatística. São Paulo: Edgard Blücher, 264 p. 1977.

DE TONI, D.; MATTIA, A. A.; LARENTIS, F.; SILVA, M. G. R. Um Estudo sobre a Configuração da Imagem do Conceito de Consumo Consciente. In: Encontro Nacional da Associação Nacional de Pós-Graduação e Pesquisa em Ambiente e Sociedade, 5, 2010, Florianópolis. Anais.... Florianópolis: UFSC, 2010.

DIAS, R. Sustentabilidade: origem e fundamentos; educação e governança global; modelo de desenvolvimento. São Paulo: Atlas, 2015.

FABI, M. J. S., LOURENÇO, C. D. S. \& SILVA, S. S. Consumo Consciente: a atitude do cliente perante o comportamento socioambiental empresarial. In: Encontro de Marketing da Associação Nacional Pós-Graduação em Administração, 4, 2010, Florianópolis. Anais... Florianópolis: UFSC, 2010.

FERNANDES, R. S. et al. Uso da percepção ambiental como instrumento de gestão em aplicações ligadas às áreas educacional, social e ambiental. Encontro Nacional de Pós-Graduação e Pesquisa em Ambiente e Sociedade, v. 2, n. 1, p. 1-15, 2004.

FOWLER JR., F. Pesquisa de levantamento. Porto Alegre: Penso, 2011.

FRÓES, C. Q.; MILANEZI, C. H. S.; BOGARIM, E. P. A. Percepção ambiental do campus universitário na faculdade de Ciências biológicas e ambientais da UFGD, In: Congresso Brasileiro De Gestão Ambiental, 2, Londrina, Anais... Londrina, PR, 2011.

GIL, A. C. Métodos e técnicas de pesquisa social. 6 ed. - São Paulo: Atlas, 2008.

JACKSON, T. Negotiating Sustainable Consumption: A review of the consumption debate and its policy implications, Energy \& Environment, v. 15,

ParaOnde!?, Porto Alegre, v.13, n.2, p.28-42, 2020.http://seer.ufrgs.br/paraonde Edição Especial - VII Seminário Internacional de Estudos Fronteriços 
n. 6, p. 1027-1051, 2004.

MARQUES M.; MARCHETTO M.; TEMPONI J. R.; FERREIRA LEITE S. C. A Percepção Ambiental pelos Alunos da UFMT- Campus Cuiabá como Instrumento de Planejamento de Sistemas de Gestão Ambiental nas Empresas. E\&S - Engineering and Science, v. 2, n. 1, 2014.

OLIVEIRA, Maxwell Ferreira de. Metodologia científica: um manual para a realização de pesquisas em administração. Catalão: UFG, 2011.

ROBBINS, S. P.; DECENZO, D. A. Fundamentos de administração: conceitos essenciais e aplicações. 4 ed. São Paulo: Prentice Hall, 2004.

SILVA, M. E.; OLIVEIRA, A, P, M.; GÓMEZ, C. R. P. Indicadores de Consumo Consciente: uma avaliação do recifense sob a ótica do consumo sustentável. Revista Eletrônica de Ciência Administrativa - RECADM, v.12, n.2, p.173190, Campo Largo/PR, Mai/Ago, 2013.

SORRENTINO, M.; NASCIMENTO, E.; PORTUGUAL, S. Universidade, Educação Ambiental e Políticas Públicas. In: Visões e experiências iberoamericana de sustentabilidade nas universidades: desdobramentos do $3^{\circ}$ Seminário Internacional de Sustentabilidade $n$ Universidade. São Carlos/SP: USP/UAM/PUCRS. 2011. p.19-28.

UNEMAT. Planejamento Estratégico Participativo 2015-2025. 2016
Disponível <http://portal.unemat.br/media/files/Documento\%20Final\%20PEP\%20CONSUN 1\%20-10-10-16.pdf > Acesso em: 20 dez 2018

UNEMAT. Plano de Desenvolvimento Institucional 2017-2021. 2017. Disponível em: <http://portal.unemat.br/media/files/PDI\%202017-2021.pdf> Acesso em: 20 dez 2018.

WCED. Our Common Future. Oxford: Oxford University Press, 1987. 